\title{
Housing: an Under-Explored Influence on Children's Well-Being and Becoming
}

\author{
Amy Clair ${ }^{1}(1)$
}

Accepted: 30 March 2018 / Published online: 9 April 2018

(C) The Author(s) 2018

\begin{abstract}
Research on housing has tended to focus on adult outcomes, establishing relationships between housing and a number of aspects of health and well-being. Research exploring the influence of housing on children has been more limited, and has tended to focus on adult concerns around risk behaviours, behavioural problems and educational attainment. While these outcomes are important, they neglect the impact of housing on children's lives beyond these concerns. There are a number of reasons to believe that housing would play an important role in children's well-being more broadly. Family stress and strain models highlight how housing difficulties experienced by adults may have knock on effects for children, while Bronfenbrenner's ecological approach to human development emphasises the importance of children's experiences of their environments, of which the home is among the most important. This paper summarises the existing evidence around housing and child outcomes, predominantly educational and behavioural outcomes, and argues for the extension of this work to consider the impact of housing on children's lives more broadly, especially their subjective well-being.
\end{abstract}

Keywords Child well-being $\cdot$ Well-becoming $\cdot$ Housing $\cdot$ Home $\cdot$ Education

\section{Introduction}

There is a substantial body of literature on the importance of housing for the health of adults. Research has demonstrated the importance of housing quality and conditions (Krieger and Higgins 2002; Shaw 2004; Jones-Rounds et al. 2014), affordability (Taylor et al. 2007; Pollack et al. 2010; Mason et al. 2013; Bentley et al. 2016; Clair et al. 2016a, 2016b), and stability (Oishi and Schimmack 2010; Burgard et al. 2012;

Amy Clair

amy.clair@essex.ac.uk

1 ESRC Research Centre on Micro-Social Change, Institute for Social and Economic Research, University of Essex, Wivenhoe Park, Colchester, Essex CO4 3SQ, UK 
Desmond and Tolbert Kimbro 2015; Beer et al. 2016; Rojas and Stenberg 2016; Wood et al. 2015) in particular. More recently, literature has begun to explore the significance of adult's housing experiences for their well-being more broadly, including their subjective well-being (Clapham 2010; Clapham et al. 2017; Foye et al. 2017; Smith et al. 2017). One area that has yet to be adequately studied is the housing experiences of children and the impact of these experiences on their well-being (Harkness and Newman 2005; Solari and Mare 2012). Research on the impact of housing on children has tended to focus on adult concerns around behaviour and attainment, rather than on children's well-being in the present as experienced by children themselves. As concerns grow about a housing crisis in the UK and beyond, comprehensive study of the relationship between housing and children's lives is timely. This paper begins by briefly introducing the concepts of child well-being and well-becoming, before exploring why a relationship between children's housing experiences and well-being is likely. It then summarises the existing knowledge regarding housing and children's lives, with particular reference to housing tenure, housing mobility and housing quality. Evidence is predominantly from wealthy countries, particularly the UK and USA. Neighbourhood influences are mentioned briefly where appropriate but cannot be comprehensively covered as the focus is on the impact of individual homes. It finishes with a call for future research and a brief discussion of directions that this might take.

\section{Child Well-Being and Becoming}

As Bradshaw (2015) has argued, it is essential to understand what influences children's well-being if we are to be able to improve it, and the twenty-first Century has seen a significant increase in the interest in the study of child well-being. Well-being is a multidimensional concept that relates to a person's quality of life. It emerged as a counter to the dominance of deficit approaches to psychology, which focused on negative outcomes such as depression (Diener 1984). This is particularly relevant to studies of children's well-being, which has sought to move away from research focused on adult concerns about children, typically focusing on risk behaviours and negative adult outcomes (Ben-Arieh et al. 2001; Ben-Arieh 2006).

These adult concerns, it has been argued, in many cases better reflect children's well-becoming, i.e. their future well-being, than their well-being in the present (Ben-Arieh 2006; Frønes 2007). This distinction between present and future well-being has been an important component of studies of child well-being, with authors highlighting the potential conflict between the two. For example school attendance may cause children unhappiness in the present but is typically essential for future labour market performance and well-being in adulthood. Together, child well-being and becoming represent children's "total well-being" (Ben-Arieh and Frønes 2011), providing a complete overview of children's lives, and as such one should not be neglected in favour of the other.

Child well-being has been operationalised in a number of ways, but large-scale studies often break children's well-being down into a number of dimensions covering objective well-being, such as health and education, accompanied by a subjective well-being dimension (Unicef 2007; Bradshaw et al. 2007; Bradshaw and Richardson 2009; OECD 2009; Unicef 2013; Unicef 2016). Housing has featured as an objective 
component in some studies of children's well-being (e.g. Bradshaw and Richardson 2009), and is likely an important influence on other objective aspects of well-being. Beyond objective well-being, it is likely that housing plays a role in children's subjective well-being (Bradshaw et al. 2013, discussed in more detail below). Subjective well-being is typically thought to consist of two main components: hedonic and eudaimonic. The hedonic component is the most frequently studied, and relates enjoyment of life. It consists of a cognitive element, typically thought of as life satisfaction, and an affective element, which itself consists of positive and negative affect (Diener 1984). Eudaimonic well-being approaches focus on autonomy, purpose and control (Ryan and Deci 2001).

\section{Why might Housing Matter?}

There are many reasons to believe that there is an important relationship between housing and child well-being. The established relationship between housing and adult outcomes makes a relationship for child outcomes likely through both direct and indirect pathways.

Children's homes are a key component of their environment. Bronfenbrenner's (1979) ecological approach to human development posits that children develop alongside their environments, and emphasises the significance of children's experiences and perceptions of their environments to their well-being. It is argued that these environments consist of a collection of nested settings, where the microsystem is the collection of settings with the greatest influence on children, of which the home is a key component. Individual environments are important, but so too are the connections between environments. Evidence of this role for housing can be found in research demonstrating the important role of housing in accessing other important public services, such as its gatekeeping role in accessing schools, health care and public transport (e.g. Gingrich and Ansell 2014). Beyond this developmental role, the causal pathways for direct influences of housing, such as the impact of poor quality housing on health, are likely to be similar for children and adults. The impact of damp on respiratory conditions, for example, has been found to affect children and adults (Beasley et al. 2015). Similarly, high housing costs will crowd out spending on other essentials, including food and educational resources, with implications for children as well as adults. Children are aware of and affected by family financial difficulties (Ridge 2002).

Indirectly, housing may impact children through several processes. Housing problems have been found to cause stress and impaired functioning among adults (Sandel and Wright 2006). This may go on to affect children through emotional contagion (Larson and Almeida 1999), where the stress is transferred from parents to children through proximity and shared environment. Negative emotions are thought to transmit more readily between people than positive ones (Larson and Almeida 1999; Larson and Gillman 1999), and there is evidence of parental depression and mental health problems affecting children's outcomes (Downey and Coyne 1990; Mensah and Kiernan 2010). Similar to theories of emotional contagion, family stress/process models emphasise the impact of (particularly economic) difficulties on family relations and child development, which also supports the hypothesis of an important role for housing on children's 
well-being (Kull and Coley 2014). Researchers have argued that stresses can have negative impacts on parental relationships and parenting behaviour, with impacts for children (Conger et al. 1992, 1993). While this approach has found support in research (e.g. Conger et al. 1992, 1993; Solantaus et al. 2004), other work has highlighted the conflict between the benefits of high housing spending, which enables families to access better quality housing and neighbourhoods, and the stress and strain caused by expensive housing (Kull and Coley 2014). Comprehensive study of the influence of housing on children's well-being will help to disentangle these conflicts and enable better understanding of the role of housing.

The following sections outline the existing evidence of the influence of housing on children's lives based on a review of the literature. Literature was collected based on Google Scholar searches of terms such as 'housing and "child well-being", and through identification of relevant papers in bibliographies of selected papers. The review was not intended to be systematic, in part because of the range of disciplines the evidence is drawn from, but does aim to provide an accurate overview of the literature. It is focused on literature published in English during the last 25 years where the research was focused on child outcomes, or family outcomes where some child-specific outcome was included. The majority of the research is quantitative but some qualitative results are included, reflecting the evidence base. Evidence has been categorised for clarity, but overlaps between categories of evidence (for example residential mobility and tenure, or overcrowding and quality) remain, and are important.

\section{Existing Evidence: Residential Mobility}

One aspect of housing experiences that has received relatively more attention for its potential impacts on children is residential mobility, or home moves. For example, a special issue of Longitudinal and Life Course Studies recently explored the impact of residential mobility on a variety of children's outcomes including cognitive outcomes and behavioural problems. These papers highlight the importance of considering the circumstances of moves, rather than assuming that residential mobility reflects a household exercising choice, moving for better and more appropriate housing (Lennon et al. 2016).

Gambaro and Joshi (2016) explored the impact of family moves on children's behavioural problems and cognitive ability at age 5 using data from the Millennium Cohort Study. This paper finds negative impacts of moving but argues that these impacts are better explained by the stressors that caused the moves, such as family structure or employment change, or insecure housing, rather than the moves themselves. Where families moved to was also important, as moving into poor areas was associated with adverse child outcomes (Gambaro and Joshi 2016). A similar paper, focusing on the US where residential moves are more common, also found that the circumstances surrounding residential moves are more important for child behaviour and cognition than the moves themselves (Beck et al. 2016).

However, these papers focused on a young age group, and the impact of moving is likely to be different depending on the age of the children studied. It may be that as children get older and become more aware of their local environment and have 
established friendship groups, for example, they have more to lose from residential mobility. In their systematic review of the influence of residential mobility on child outcomes, Jelleyman and Spencer (2008) reported evidence of increased behavioural problems among those who had moved three or more times among a sample of 1112 year-old Canadian children. Similar results were also found among US children, but not in a British sample. Among older children, Jelleyman and Spencer (2008) reported increased risk behaviours, such as drug use and teenage pregnancy, in North American samples. There is also evidence of long-term impacts lasting into adulthood. In a US investigation of the impact of childhood residential moves, Oishi and Schimmack (2010) found that moves affected people's subjective well-being well into adulthood, but that this effect was dependent on personality type.

Moves can also disrupt the relationship between children and health care. For example, Pearce et al. (2008) found that children who had moved more frequently were less likely to have received all of their vaccinations. Evidence of lack of continuity was also reported by Jelleyman and Spencer (2008) for children and young people in the US, but not Finland. Brown et al. (2012) studied the association between residential moves and health more generally for children in Scotland. They found poorer mental health among movers, which was partly explained by school mobility.

Despite these frequently negative findings, the notion of a positive impact of moving, particularly to a 'better' neighbourhood, remains prevalent and forms the basis for many housing policies in North America, such as the Moving to Opportunity and Gautreaux programs. Moving home is often, although not always, associated with moving schools, and as such has been of interest to education researchers. In some cases, particularly in places like the USA and, arguably, the UK, changing schools may be the goal of a residential move. In other cases a school move may not be accompanied by a residential move at all (Pribesh and Downey 1999).

Pribesh and Downey (1999) explored the relationship between school and home moves and educational achievement, hypothesising that the negative relationship identified in previous research was explained by reduced social capital following mobility. In their sample of high-school-aged children in the US, they found that mobility was associated with a decrease in social capital, which in turn partly explained the lower educational performance of movers. However, differences between movers and non-movers, evident before the move takes place, explain most of the differences. In a similar study, Swanson and Schneider (1999) found that the timing of a move affected the impact of mobility on achievement, with moves in early high school having no effect, but moves late in high school having negative consequences for achievement. They highlighted the importance of treating school moves and residential mobility as different events, and found an increased risk of high school dropout among movers, although proactive changes to schooling early in high school could have protective effects on the risk of drop out. Another positive outcome for childhood mobility was found in a Canadian study investigating the impact of 'community moves' on educational attainment amongst adults (Hango 2006). This paper found a positive impact of moves on the educational attainment of adults. However the different operationalisation of mobility should be noted, and thought given to whether the long-term benefits to educational attainment outweigh the shorter-term negative consequences for children and young people. 
Residential mobility is a clear example of where housing may exacerbate existing disadvantage. Frequent moving is more common among disadvantaged groups (Scanlon and Devine 2001; Crowley 2003; Brown et al. 2012; Ziol-Guest and McKenna 2014; Clark 2016; Lupton 2016), and it is often the children of these disadvantaged groups that experience the worst outcomes when experiencing residential mobility (e.g. Hofferth et al. 1998; Ziol-Guest and McKenna 2014). As such, residential mobility may be playing an important role in the repetition and reinforcing of social inequalities (Scanlon and Devine 2001). Government policy encouraging mobility, for employment for example, may be overlooking some of the negative consequences faced by children because of this approach (Pribesh and Downey 1999).

\section{Existing Evidence: Insecurity and Instability}

A related area of concern is housing insecurity and instability. In comparison with residential mobility, which tends to focus on the frequency of moves, instability and insecurity are broad terms concerned more with strains on housing, including issues such as affordability and quality, which affect the continuity of housing. It takes into account the relationship between different forms of housing difficulties that can affect housing continuity, for example unaffordable housing causing frequent moves or leading to eviction (Warren and Font 2015).

In the US, families involved with Child Protective Services are disproportionately likely to live in insecure housing. Warren and Font (2015) investigate this relationship using Fragile Families and Child Well-Being data, using data for children aged 3 and 5 years. In their analysis they find that housing insecurity, operationalised as having experienced eviction or homelessness or multiple moves in the past year, is associated with increased risk of child neglect. This association is found to be mediated by maternal stress. Housing affordability was not found to be statistically significantly related to risk of abuse or neglect directly, however the association was found to be mediated by parental stress. These results support the family stress model but also indicate that housing insecurity has a unique influence on child maltreatment risk.

In a review of predictors of asthma diagnosis, Sandel and Wright (2006) make the case for looking beyond the physical characteristics of housing when trying to understand asthma morbidity. They point to evidence that stressful events, such as housing insecurity, experienced by the child themselves or by their caretakers, are linked with increased risk of respiratory problems. Stress is directly associated with impaired immune system function, but also affects children's health indirectly as caregivers experiencing high levels of stress are not able to attend to children's health needs, for example asthma management, as adequately.

\section{Existing Evidence: Housing Tenure}

Housing tenure relates to the legal basis through which a person comes to inhabit, and the rights that they have to remain in, their home. However tenure is often used to proxy a range of other individual characteristics, and is often conflated with other elements of housing such as quality (Barlow and Duncan 1988). A number of 
researchers, particularly economists, have explored the benefits of living in owner occupied homes for children and young people. In many countries, including the UK and USA, homeownership is supported and encouraged through housing policies (Haurin et al. 2002; Ronald 2008).

A number of early studies found statistically significant links between housing tenure and child outcomes. One high profile paper, Green and White (1997), explored the educational attendance and teen pregnancy outcomes of 17 and 18 year-olds in the US. Their results indicated that the children of owner occupiers were more likely to stay in school and less likely to have children as teenagers (Green and White 1997). In a similar study, again focusing on young people in the US, Boehm and Schlottmann (1999) found that the children of owner occupiers achieve higher levels of education in the ten years after leaving the parental home. In a Canadian study of housing tenure, Boyle (2002) investigated the relationship between owner occupation and behaviour problems for 4-16 year-olds in Ontario. Results indicated that owner occupation was associated with lower levels of behaviour problems, but around two thirds of this association was explained by socio-economic status (Boyle 2002).

These papers have been criticised for failing to control for all relevant factors. Aaronson (2000) argued that Green and White's finding is due to omitted variable bias. Recreating their analysis, he finds that the impact of homeownership on likelihood of graduating high school is greatly diminished once the frequency of residential moves is accounted for, while wealth also explained some of the difference. Home ownership is statistically insignificant in models which include an instrumental variable, homeownership rates for different groups, to account for the endogeneity between tenure and mobility. Haurin et al. (2002) make a similar criticism of Boehm and Schlottmann's analysis, and again conduct their own analysis. This paper focuses on the role of home quality, for example noting that lead from paint or water pipes has been linked with children's cognitive outcomes and development, and that children are more likely to be exposed to lead in rented homes as these tend to be older and more distressed. Again using a US sample, they find a positive relationship between ownership and home quality, and between home quality and educational achievement, although these results were only statistically significant at the $10 \%$ level, and results for behavioural problems were not significant. The importance of home environment to this result suggests that tenure is less important than home quality for child outcomes.

Galster et al. (2007) investigate the impacts of living in owner occupied homes during childhood on young adult outcomes, up to the age of 31 , in order to assess the cumulative impact of childhood tenure. They find that any effects of parental homeownership on educational outcomes, measured as receiving a high school diploma or college degree, is insignificant once residential stability is accounted for in the models. They argue that by choosing to own a home, owners are also choosing longer, more secure residency, and therefore the effect of homeownership is important. However this is a disputable assumption.

A more recent study by Holupka and Newman (2012) investigated the role of selection effects on the impact of ownership on child outcomes among low-income ethnic minority households using data from the USA. They use a matching and instrumental variable approach and focused on educational ability, behaviour problems and health as outcomes. Instead of using a measure of current housing 
tenure, Holupka and Newman (2012) treat homeownership as the fraction of a child's life spent living in an owner occupied home. An important finding in this paper was that experiences of homeownership, and the benefits accumulated, varied for different groups. For example, residential stability is thought to be one of the advantages of ownership, but black home owners were found to have a shorter length of residency than white owners. Similarly, black children who moved into owner occupation did not experience the same increase in cognitive scores as white children, nor the same reduction in behaviour problems. In terms of the impact of ownership itself different results are found for children of different ethnicities. A homeownership effect on cognitive performance was found for white and Hispanic children but not for black children. No mediating effects of residential stability, parental or neighbourhood characteristics were found.

Baker et al. (1998) used the Avon Longitudinal Study of Pregnancy and Childhood (ALSPAC) to explore respiratory and gastrointestinal problems at up to 6 months of age. Both wheezing and gastrointestinal issues were more likely among children living in rented homes compared to those living in owner occupied homes. However in this study rented accommodation was treated as a proxy for low income and deprivation in the absence of income data, and so it is unclear whether this result is due to tenure. Overall, these results highlight the importance of treating tenure and other aspects of housing, such as stability and quality, separately to accurately understand the role of housing in people's lives. There is also potential for increased nuance in the study of tenure. Research has tended to use an owned versus rented dichotomy, failing to consider within tenure variation. For example, one study exploring adult health in Canada found that those living in co-operatively owned or tenant managed (often referred to as condominium) homes reported better self-rated and mental health, as well as higher health satisfaction, than those that didn't (Dunn and Hayes 2000). There are similar differences within renting, such as social and private rent, type of landlord, and others.

\section{Existing Evidence: Overcrowding}

Overcrowding relates to the amount of housing available to individual members of a household. It is typically measured according to the number of rooms per person, and concerns around overcrowding revolve around privacy, disturbed sleep, and personal space. Across the EU-28, 23.8\% of households with children were living in overcrowded homes in 2016 (Eurostat 2017a).

Research has focused predominantly on the effect of overcrowding on adults (Leventhal and Newman 2010), although research has explored the impact of crowded housing on children's educational, behavioural and health outcomes. A study of overcrowding in Taiwan explored the possibility that overcrowding affects ability to study through reduced privacy and peace, with consequences for attainment (Lien et al. 2008). Lien et al. (2008) studied the educational level of 16-17 and 19-20 year olds in Taiwan living in nuclear families, using the national census. Results indicated a positive relationship between floor space and educational outcomes, and between children having a private bedroom and educational outcomes, but the study did not account for income. 
Park et al. (2011) used Fragile Families data to investigate the impact of families living 'doubled up' - those living with friends or family but not paying rent or who had moved in with other people because of financial difficulties. They found that emotional and behavioural problems were more common among doubled up children than housed low-income children, but no there was no increased risk of physical health, mental health, cognitive development issues or health care usage. Another US study (Solari and Mare 2012) focused on overcrowding as persons per room over a 4 year period. Pooled OLS analysis and found that overcrowding negatively impacted maths and reading test scores. Statistically significant $(p<.05)$ results were not found for physical health or behaviour problems. When fixed effects regression analysis was conducted the only statistically significant finding was an increase in problematic externalising behaviour.

There have been similar studies in the UK. In Baker et al.'s (1998) study using ALSPAC data, they found that wheezing was more likely in children up to the age of 6 months that lived in rented or crowded housing, with crowding measured as number of people per room. Coggon et al.'s (1993) study used the 1936 Chesterfield housing survey, National Health Survey (between 1951 and 1989) and (1939) Census data. They found that among those who were children at the time of the 1936 survey, death rates were higher among those that lived in overcrowded homes (people per bedroom) or homes with no running hot water. While the approach used in this study has many advantages, notably that it does not rely on people being able to recall their housing situation during their childhood, the data about the home and household is limited, length of time at address for example is not available, and household size information relates only to one time point.

\section{Existing Evidence: Housing Quality}

Housing quality is an area of housing that has received a lot of attention in literature exploring the impact of housing on adult outcomes. However there are additional concerns regarding housing quality for children's lives. Perhaps most notable is the link between housing quality and intervention by social services, as poor quality housing is often treated as a form of child neglect (Warren and Font 2015). Across the EU-28 $16.9 \%$ of households with children live in a home where there is one or more of: leaking roof, damp walls, floors or foundation, or rot in window frames or floor (Eurostat 2017b).

In Coley et al.'s (2013) comprehensive study of housing in relation to school outcomes and behaviour, they find that housing quality was the most important of the housing measures they considered in terms of impact on child outcomes. Housing quality issues were defined as at least one of: leaking roof, broken windows, rodents, heater or stove not working, peeling paint or exposed wiring. Mixed results were found for residential moves, while no effect was found for housing cost burden directly. In their review of risk factors for childhood asthma, Beasley et al. (2015) reported that children living in homes that suffered from damp or mould were at high risk of developing asthma. As noted above, Haurin et al. (2002) found an important relationship between housing quality and educational outcomes. Evans et al. (2001) took a broader view of housing quality in their study, including privacy and cleanliness in their measure. In their study of a predominantly white sample of low to middle-income children from New York, they found that better housing quality was associated with 
reduced likelihood of behavioural problems and higher task persistence among children in third through fifth grades.

\section{Existing Evidence: Housing Affordability}

High housing cost burden - typically indicated by spending over $30 \%$ of household income on housing - disproportionately affects low income households (Kull and Coley 2014; Warren and Font 2015). Spending on housing has important consequences for children and families. Higher spending may enable access to better quality housing, that is safer and in a better neighbourhood. But spending on housing crowds out spending on other essentials such as food, clothing and educational resources, as well as being a source of stress. Housing costs are an important determinant of whether children live in poverty. In the UK for example, $20 \%$ of children were living in relative poverty in 2015/16 before housing costs compared to $30 \%$ after housing costs were taken into account, equating to an additional 1.3 million children experiencing poverty due to housing costs (DWP 2016).

Research has explored the impact of high housing costs on children's outcomes. Harkness and Newman (2005) took an ecological approach, studying the presence of affordable housing in low-income children's neighbourhoods in the USA. They hypothesised that unaffordable housing might affect children through reduced consumption of other necessities, or through the stress placed on parents. The outcome of interest was child well-being, operationalised using a range of objective measures including health, educational engagement, and behaviour (Harkness and Newman 2005). Their results indicate that better housing affordability is associated with better health and grade retention (i.e. not being held back a school year) for 6 to 11 year olds. For older children, aged 12-17, positive effects were found for health, behaviour problems, grade retention, and school engagement, suggesting that housing affordability difficulties have wider ranging impacts on older children (Harkness and Newman 2005). Results also provided greater support for the hypothesis that housing affordability affects children through material deprivation, rather than family stress, as well as indicating that it is low income children that are most affected by unaffordable housing.

Kull and Coley (2014) considered housing as a family investment, emphasising the conflict between spending more on housing and therefore living in a better quality home, and financial strain caused by high housing costs. Their study covered low income families in 3 US cities, with children aged 0-4 or 10-14. Results demonstrated no direct relationship between housing spending (as a percentage of income) and internalising or externalising behaviour, but did find an effect mediated by higher neighbourhood quality and, to a lesser extent, reduced housing problems. Housing costs were negatively associated with reading skills, but this was mediated by improved neighbourhood, no association was found for maths skills.

\section{Existing Evidence: Financial Support for Housing}

Government support in accessing quality affordable housing varies across nations. Evidence relating to the impact on children is limited, but most comes from the UK 
and USA. There are similarities in these countries, with support having previously taken a supply based approach that has moved towards an individual household financial support approach (Currie and Yelowitz 2000).

In the UK support for housing comes in two forms. Social housing is housing provided by a Local Authority or Housing Association below market rent. It is managed by the Local Authority or Housing Association and is typically higher quality than housing available in the Private Rented (market) Sector (DCLG 2017). Social and Private tenants may also access Housing Benefit, depending on their income and rental costs. Housing Benefit is a benefit payment intended to make housing more affordable. In the USA housing support is more varied, but is typically provided through housing vouchers and public housing 'projects'. Similar to social housing in the UK, housing projects are public housing with eligibility based on income and rents below the market rate (linked to income) (Currie and Yelowitz 2000). The Housing Choice Voucher Program is the largest housing assistance program (Wood et al. 2008). It provides subsidy to meet rents in the private sector, in homes that meet a quality and affordability standard, and which is let by a landlord willing to accept tenants using vouchers. However housing vouchers are very limited, and only a fraction of those in need of support actually receive financial assistance. In addition, not all households that receive a voucher will be successful in using it, as they may struggle to find accommodation that meets affordability and quality standards (Wood et al. 2008).

A number of studies have explored the impact of housing support on children's outcomes in the USA. Kull and Coley's (2014) analysis found a different link between housing cost burden and child outcomes for those living in public or voucher subsidised ("assisted") housing compared to those living in unassisted private rental housing. They found that higher housing spending enabled access to better neighbourhoods and housing only for those in unassisted housing. The impacts on child outcomes also varied across housing types. Among the unassisted group, a direct positive association was found between housing costs and externalising problems, while the relationship between neighbourhood disadvantage and internalising behaviour was larger for those living in assisted housing.

Currie and Yelowitz's (2000) study of children in the USA living in project housing found advantages to this type of housing, noting that families living in project housing are less likely to experience overcrowding. Their analysis of data from the early 1990s found that children in project housing were less likely to have been held back a grade at school, but this is only statistically significant at the $10 \%$ level, and it is likely this effect was only true for boys and not for girls. Benefits are also found to be greater where household incomes are lower and the head of household has a low level of educational attainment.

A further study in this area was an experimental evaluation of housing vouchers for low income families. Conducted in the 2000s, it followed eligible households in 6 US cities who were randomly assigned to receive a voucher to meet their housing costs. Unlike most of the evidence discussed in this review, evidence from this project is qualitative as well as quantitative, and participants were interviewed 5 years into the study. Wood et al. (2008) found that the vouchers were associated with a range of positive outcomes including reduced homelessness, overcrowding, household size and sharing, while neighbourhood quality improved and positive mobility increased. In the survey conducted 5 years after 
the beginning of the study, $45 \%$ of those who did not receive a voucher had experienced homelessness compared to $9 \%$ of those that did receive a voucher. The equivalent figures for overcrowding were $46 \%$ and $24 \%$ respectively. In the qualitative interviews many recipients spoke of the reduction in anxiety brought about by knowing how their rent would be paid. There was also evidence that voucher recipients used them to move to better neighbourhoods and areas with better schools, for example black households in receipt of a voucher were living in neighbourhoods with an average $4 \%$ lower poverty rate than black families who didn't receive a voucher. Voucher recipients also spent more (per person) on food than those who did not receive vouchers. This evaluation also studied impacts on child well-being, operationalised as solely education related outcomes, but no statistically significant effect is found. Parents did report in the qualitative interviews that the vouchers had enabled them to spend more money on educational resources and clothes, and felt that the voucher had had a positive effect on children's emotional well-being through reduced stress.

In the UK there is evidence of the positive effects of housing support more generally. Bradshaw et al. (2008) argued that social housing in UK had been successful in reducing the link between income and poverty. However housing support now more commonly takes the form of housing payments through housing benefit as the amount of social housing declines. A recent paper by Reeves et al. (2016) investigated the impact of housing benefit reductions which took place in 2011 in an attempt to reduce government spending, costing recipients an average of $£ 1220$ per year. Results indicated that this change was associated with a statistically significant increase in depression symptoms among affected adults. As well as being problematic in its own right, this will likely have had implications for the children in these homes because, as noted above, parental depression has been linked with a number of negative child outcomes (Downey and Coyne 1990; Mensah and Kiernan 2010).

\section{Existing Evidence: The Absence of a Home}

Homelessness can cover a range of situations, from couch surfing to living in a car, temporary accommodation or rooflessness. The range of types, causes and consequences of homelessness are too great to be adequately covered here, and so a very brief summary is given. Research has found significant impacts of homelessness on children, including increased risk of chronic health conditions, undernutrition, development delays and problems with cognitive function, as well as reduced likelihood of receiving vaccinations. Park et al. (2011) studied a variety of homeless situations, including those living in a shelter, temporary housing, or 'a place not meant for human habitation' such as a car or on the street. They found that homeless children were more likely to have a physical disability and/or an emotional or behavioural problem than children who were not homeless. No differences were found for cognitive development, mental health, or health care use. However evidence is not always clear that homeless children fare worse than children who are poorly housed or living in low-income families (Masten et al. 1993; Park et al. 2011). 


\section{Problems with Existing Housing Evidence}

This paper has summarised a range of evidence relating to the influence of housing on children. However, the overwhelming focus of this research has been on risk behaviours, behavioural problems and cognitive or educational outcomes. There is a dearth of research has on subjective elements of child well-being. While objective well-being and well-becoming are important, the absence of research on subjective well-being is problematic. There has also been a tendency in the research to focus on children in low-income households. Studying children from all backgrounds will enable comparison across different groups. Housing is central to family life (Crowley 2003), and therefore is likely to play an important role in all children's lives, including all children in research on housing will confirm or refute this.

Analyses that include multiple housing dimensions have also demonstrated the importance of considering different elements of housing simultaneously, for example Haurin et al.'s (2002) findings highlight the importance of housing quality when understanding the influence of tenure. Future research should include a range of housing dimensions in order to more accurately understand their influence, and how different housing characteristics interact with one another to influence children's outcomes.

There are also important limitations to currently available data. An important part of future research should be expanding data collection on children's housing, including information from children themselves about the suitability and satisfaction with their housing, and recognising that children may be resident in multiple homes due to family structure.

\section{Housing in Studies of children's Well-Being}

Housing has featured as a dimension of child well-being in a number of international studies, and results support a potentially important role for housing in broader well-being. For example, in Doing Better for Children (OECD 2009) housing and environment was included as one of 6 dimensions. Indicators of overcrowding and environmental conditions (noise in the home and local area; dirt pollution, litter and grime in the local area) were included. Norway and Australia were found to perform best of the countries included, and Mexico and the Slovak Republic worst. The inclusion of housing and environment in this study is justified as recognition of children's right to an adequate standard of living, as included in the United Nations Convention on the Rights of the Child (Article 27).

A very similar approach to housing was included in Bradshaw and Richardson (2009), however the environmental component also included crime, and a housing problems (one or more of leaking roof, damp walls/floors/foundations, or rot in the window frames; accommodation too dark; no bath or shower; no indoor flushing toilet for sole use of the household) measure was also included. By this measure Norway and Ireland were found to perform best, Latvia and Estonia worst. Housing was included in the study as it was a good indicator of income poverty and poverty of opportunity for children. In this study a correlation of $-0.75(p<.001)$ was found between households with children reporting more than one housing problem and overall well-being, the (joint) 4th highest correlation with overall well-being of the 43 indicators included in the study. 
The 2013 Unicef report card on child well-being in rich countries takes a similar approach to the inclusion of housing, which is again one of 6 dimensions. Housing and environment consists of overcrowding, more than one housing problem (of leaking roof, damp walls/floors/foundations, or rot in the window frames; accommodation too dark; no bath or shower; no indoor flushing toilet for sole use of the household), homicide rate, and air pollution. Here Switzerland and Ireland perform best, Latvia and Romania worst. In their 2013 study, Bradshaw et al. found a statistically significant correlation of .61 between the housing and environment domain of the Unicef Report Card 11 and subjective well-being using Health Behaviours in School-Aged Children data. A similar link between housing situation and subjective well-being was found in a recent UK study. Rees and Bradshaw (2017) found a number of housing-related variables were significantly associated with reporting low subjective well-being (cognitive and affective) among children aged 11. Children living in rented homes were more likely to report low subjective well-being than those living in homes owned by their parents (no distinction was made between social and private rent or homes owned with a mortgage and owned outright). Similarly, children having their own space to do homework and access to local parks were also found to be important.

\section{Housing and children's Well-Being and Becoming: Why Now?}

While research on the impact of housing on children has focused on objective well-being and well-becoming, the substantial evidence of the impact of housing on adults indicates that housing is likely to play a broader role in children's lives. But it is not adequate to assume that this is the case, children are deserving of study in their own right (Ben-Arieh et al. 2001; Ben-Arieh 2006; Frønes 2007). Importantly, housing is an area of children's lives which is highly policy amenable, and therefore an area which, if studied, can be manipulated to improve children's lives. One major way that government could do this for children in the UK is to improve conditions in the Private Rented Sector (PRS), an area of particular concern.

As availability of socially rented housing decreases while increasing house prices and requirements for larger mortgage deposits make home ownership less accessible, more families with children in the UK are living in the PRS. The fraction of households with children in the PRS trebled from $8 \%$ in 1996/7 (around 461,000 households) to over 24\% in 2014/15 (around 1,549,000 households) (DCLG 2016). This increase means that families with children are now the most common household type in the PRS (DCLG 2016). Analysis of 2011 Census data showed that $22 \%$ of families with a child under five living in the PRS were experiencing housing deprivation, compared to just $7 \%$ of those living in owner occupied homes (Lupton 2016). The most recent English Housing Survey also found considerable differences in housing standards across tenures. It showed that $28 \%$ of PRS homes failed to meet the Decent Homes Standard (a government defined minimum standard for homes), compared to $13 \%$ of socially rented homes (DCLG 2017), an important difference given the link between home quality and children's outcomes found by Haurin et al. (2002). As well as lower quality housing costs in the PRS are also higher than in other tenures, mean weekly rents are $£ 184$ in the PRS compared to $£ 101$ in the social sector (DCLG 2017, figures for England), with implications for the number of children living in poverty and 
experiencing financial strain. Insecurity is also greater in the UK PRS, a recent report by Citizens Advice Bureau ( 2017) found that $39 \%$ of people with children in the PRS are living in their home with a tenancy period of 6 months or less.

The increase in children in the being raised in the PRS, and accompanying shift in their housing experiences, means that understanding the influence of housing on children's well-being is important. Despite the evidence linking specific housing issues to some child outcomes, and the large and statistically significant correlations between housing dimensions and overall/subjective well-being in comparative child well-being studies, the role of housing in children's well-being and becoming remains under-explored. In particular there is a need for longitudinal studies (Coley et al. 2013) which take into account the nuanced ways in which housing can impact children's lives. For example distinguishing between 'advantaging' and 'disadvantaging' moves (Lupton 2016), understanding the causes of residential mobility rather than treating all moves as equal. It will need to consider the conflict between higher housing costs as a means of obtaining better quality housing and as a source of financial difficulty. A further consideration will be the role played by housing in exacerbating other forms of inequality and disadvantage, while ensuring that overlaps and interactions between different housing issues are explored. This expansion of private renting is not unique to the UK (Arundel and Doling 2017), and comparative study of the impact of housing on children may be one means of studying how housing ameliorates or exacerbates inequalities depending on housing policy. It is also essential that research better integrates children's own perceptions of their well-being and environments (Bronfenbrenner 1979), remembering that the role of housing in children's lives will likely vary over the life course and for children from different backgrounds. Given the shifts in the housing market following the recent financial crisis, which particularly affected families with children (Lupton 2016), research on housing and child well-being has never been more timely.

Acknowledgements This work was supported by the Economic and Social Research Council [ES/ L009153/1]. The author would like to thank Charlotte Hamilton for her helpful feedback on the paper.

Open Access This article is distributed under the terms of the Creative Commons Attribution 4.0 International License (http://creativecommons.org/licenses/by/4.0/), which permits unrestricted use, distribution, and reproduction in any medium, provided you give appropriate credit to the original author(s) and the source, provide a link to the Creative Commons license, and indicate if changes were made.

\section{References}

Aaronson, D. (2000). A note on the benefits of homeownership. Journal of Urban Economics, 47, 356-369.

Arundel, R., \& Doling, J. (2017). The end of mass homeownership? Changes in labour markets and housing tenure opportunities across Europe. Journal of Housing and the Built Environment, 32, 649-672.

Baker, D., Taylor, H., Henderson, J. and the ALSPAC Study Team (1998) 'Inequality in infant morbidity: causes and consequences in England in the 1990s', Journal of Epidemiology and Community Health, Vol. 52, pp. 451-458.

Barlow, J., \& Duncan, S. (1988). The use and abuse of housing tenure. Housing Studies, 3(4), $219-231$.

Beasley, R., Semprini, A., \& Mitchell, E. A. (2015). Risk factors for asthma: is prevention possible? Lancet, 386, 1075-1085.

Beck, B., Butter Jr., A., \& Lennon, M. C. (2016). Home moves and child wellbeing in the first five years of life in the United States. Longitudinal and Life Course Studies, 7(3), 240-264.

Beer, A., Bentley, R., Baker, E., Mason, K., Mallett, S., Kavanagh, A., \& LaMontagne, T. (2016). Neoliberalism, economic restructuring and policy change: precarious housing and precarious employment in Australia. Urban Studies, 53(8), 1542-1558. 
Ben-Arieh, A. (2006). Measuring and monitoring the well-being of young children around the world. Paper commissioned for the EFA global monitoring report 2007, strong foundations: early childhood care and education. UNESCO.

Ben-Arieh, A., \& Frønes, I. (2011). Taxonomy for child well-being indicators: a framework for the analysis of the well-being of children. Childhood, 18(4), 460-476.

Ben-Arieh, A., Hevener Kaufman, N., Bowers Andrews, A., George, R. M., Joo Lee, B., \& Aber, J. L. (Eds.). (2001). Measuring and monitoring children's well-being. London: Kluwer Academic Publishers.

Bentley, R. J., Pevalin, D., Baker, E., Mason, E., Reeves, A., \& Beer, A. (2016). Housing affordability, tenure and mental health in Australia and the United Kingdom: a comparative panel analysis. Housing Studies, 31(2), 208-222.

Boehm, T. P., \& Schlottmann, A. M. (1999). Does homeownership by parents have an economic impact on their children? Journal of Housing Economics, 8, 217-232.

Boyle, M. H. (2002). Home ownership and the emotional and Behavioural problems of children and youth. Child Development, 73(3), 883-892.

Bradshaw, J. (2015). Subjective well-being and social policy: can nations make their children happier? Child Indicators Research, 8(1), 227-241.

Bradshaw, J., \& Richardson, D. (2009). An index of child well-being in Europe. Child Indicators Research, 2 (3), 319-351.

Bradshaw, J., Hoelscher, P., \& Richardson, D. (2007). An index of child well-being in the European Union. Social Indicators Research, 80(1), 133-177.

Bradshaw, J., Chzhen, Y., \& Stephens, M. (2008). Housing: the saving grace in the British welfare state? In S. Fitzpatrick \& M. Stephens (Eds.), The future of social housing. London: Shelter.

Bradshaw, J., Martorano, B., Natali, L., \& de Neubourg, C. (2013). Children's subjective well-being in rich countries. Child Indicators Research, 6(4), 619-635.

Bronfenbrenner, U. (1979). The ecology of human development. Cambridge: Harvard University Press.

Brown, D., Benzeval, M., Gayle, V., Macintyre, S., O’Reilly, D., \& Leyland, A. H. (2012). Childhood residential mobility and health in late adolescence and adulthood: findings from the west of Scotland twenty-07 study. Journal of Epidemiology and Community Health, 66(10), 942-950.

Burgard, S. A., Seefeldt, K. S., \& Zelner, S. (2012). Housing instability and health: findings from the Michigan recession and recovery study. Social Science \& Medicine, 75, 2215-2224.

Citizens Advice (2017) Families with children hit by insecurity in the PRS, http://bit.ly/2hNx7c8

Clair, A., Reeves, A., Loopstra, R., McKee, M., Dorling, D., \& Stuckler, D. (2016a). The impact of the housing crisis on self-reported health in Europe: multilevel longitudinal modelling of 27 EU countries. European Journal of Public Health, 26(5), 788-793.

Clair, A., Loopstra, R., Reeves, A., McKee, M., Dorling, D., \& Stuckler, D. (2016b). The impact of housing payment problems on health during the recession: a comparison of European nations. Soc Sci Med - Popul Health, 2, 306-316.

Clapham, D. (2010). Happiness, well-being and housing policy. Policy \& Politics, 38(2), 253-267.

Clapham, D., Foye, C., \& Christian, J. (2017). The concept of subjective well-being in housing research. Housing, Theory and Society, 1-20. https://doi.org/10.1080/14036096.2017.1348391.

Clark, W. A. V. (2016). Life events and moves under duress: disruption in the life course and mobility outcomes. Longitudinal and Life Course Studies, 7(3), 218-239.

Coggon, D., Barker, D. J. P., Inskip, H., \& Wield, G. (1993). Housing in early life and later mortality. Journal of Epidemiology and Community Health, 47, 345-348.

Coley, R. L., Leventhal, T., Lynch, A. D., \& Kull, M. (2013). Relations between housing characteristics and the well-being of low-income children and adolescents. Developmental Psychology, 49(9), 1775-1789.

Conger, R. D., Conger, K. J., Elder, G. H., Lorenz, F. O., Simons, R. L., \& Whitbeck, L. B. (1992). A family process model of economic hardship and adjustment of early adolescent boys. Child Development, 63(3), 526-541.

Conger, R. D., Conger, K. J., Elder, G. H., Lorenz, F. O., Simons, R. L., \& Whitbeck, L. B. (1993). Family economic stress and adjustment of early adolescent girls. Developmental Psychology, 29(2), 206-219.

Crowley, S. (2003). The affordable housing crisis: residential mobility of poor families and school mobility of poor children. The Journal of Negro Education, 72(1), 22-38.

Currie, J., \& Yelowitz, A. (2000). Are public housing projects good for kids? Journal of Public Economics, $75,99-124$.

DCLG (2016) Tenure trends \& cross tenure analysis, http://bit.ly/2xq2e0U

DCLG. (2017). English housing survey: Private rented sector 2015-16. London: DCLG.

Desmond, M., \& Tolbert Kimbro, R. (2015). Eviction's fallout: housing, hardship, and health. Social Forces, 94(1), 295-324.

Diener, E. (1984). Subjective well-being. Psychological Bulletin, 95(3), 542-575. 
Downey, G., \& Coyne, J. C. (1990). Children of depressed parents: an integrative review. Psychological Bulletin, 108(1), 50-76.

Dunn, J. R., \& Hayes, M. V. (2000). Social inequality, population health, and housing: a study of two Vancouver neighborhoods. Social Science \& Medicine, 51(4), 563-587.

DWP. (2016). Households below average income 2015/16. London: DWP.

Eurostat (2017a) 'Overcrowding rate by household type', Available at: http://bit.ly/2yWEFNo

Eurostat (2017b) 'Total population living in a dwelling with a leaking roof, damp walls, floors or foundation, or rot in window frames of floor', Available at: http://bit.ly/2D3qyJo.

Evans, G. W., Saltzman, H., \& Cooperman, J. L. (2001). Housing quality and children's socioemotional health. Environment and Behaviour, 33(3), 389-399.

Foye, C., Clapham, D., \& Gabrieli, T. (2017). Home-ownership as a social norm and positional good: subjective wellbeing evidence from panel data. Urban Studies, 55(6), 1290-1312.

Frønes, I. (2007). Theorizing indicators: On indicators, signs and trends. Social Indicators Research, 83(1), 5-23.

Galster, G., Marcotte, D. E., Mandell, M. B., Wolman, H., \& Augustine, N. (2007). The impact of parental homeownership on children's outcomes during early adulthood. Housing Policy Debate, 18(4), 785-827.

Gambaro, L., \& Joshi, H. (2016). Moving home in the early years: what happens to children in the UK? Longitudinal and Life Course Studies, 7(3), 265-287.

Gingrich, J., \& Ansell, B. (2014). Sorting for schools: housing, education and inequality. Socio-Economic Review, 12(2), 329-351.

Green, R. K., \& White, M. J. (1997). Measuring the benefits of home owning: effects on children. Journal of Urban Economics, 41, 441-461.

Hango, D. W. (2006). The long-term effect of childhood residential mobility on educational attainment. The Sociological Quarterly, 47, 631-664.

Harkness, J., \& Newman, S. J. (2005). Housing affordability and children's well-being: evidence from the national survey of America's families. Housing Policy Debate, 16(2), 223-255.

Haurin, D. R., Parcel, T. L., \& Haurin, R. J. (2002). Does homeownership affect child outcomes? Real Estate Economics, 30(4), 635-666.

Hofferth, S. L., Boisjoly, J., \& Duncan, G. J. (1998). Parents' extrafamilial resources and children's school attainment. Sociology of Education, 71(3), 246-268.

Holupka, S., \& Newman, S. J. (2012). The effects of homeownership on Children's outcomes: real effects or self-selection? Real Estate Economics, 40(3), 566-602.

Jelleyman, T., \& Spencer, N. (2008). Residential mobility in childhood and health outcomes: a systematic review. Journal of Epidemiology and Community Health, 62(7), 584-592.

Jones-Rounds, M., Evans, G. W., \& Braubach, M. (2014). The interactive effects of housing and neighbourhood quality on psychological well-being. Journal of Epidemiology and Community Health, $68,171-175$.

Krieger, J., \& Higgins, D. L. (2002). Housing and health: time again for public health action. American Journal of Public Health, 92(5), 758-768.

Kull, M. A., \& Coley, R. L. (2014). Housing costs and child functioning: processes through investments and financial strains. Children and Youth Services Review, 39, 25-38.

Larson, R. W., \& Almeida, D. M. (1999). Emotional transmission in the daily lives of families: a new paradigm for studying family process. Journal of Marriage and the Family, 61(1), 5-20.

Larson, R. W., \& Gillman, S. (1999). Transmission of emotions in the daily interactions of single-mother families. Journal of Marriage and the Family, 61(1), 21-37.

Lennon, M. C., Clark, W. A. V., \& Joshi, H. (2016). Residential mobility and wellbeing: exploring children's living situations and their implications for housing policy. Longitudinal and Life Course Studies, 7(3), 197-200.

Leventhal, T., \& Newman, S. (2010). Housing and child development. Children and Youth Services Review, 32, 1165-1174.

Lien, H.-M., Wu, W.-C., \& Lin, C.-C. (2008). New evidence on the link between housing environment and children's educational attainments. Journal of Urban Economics, 64, 408-421.

Lupton, R. (2016). The influence(s) of housing policies on the residential moves of families with young children. Longitudinal and Life Course Studies, 7(3), 288-301.

Mason, K., Baker, E., Blakely, T., \& Bentley, R. J. (2013). Housing affordability and mental health: does the relationship differ for renters and home purchasers? Social Science \& Medicine, 94, 91-97.

Masten, A. S., Miliotis, D., Graham-Bermann, S. A., Ramirez, M., \& Neemann, J. (1993). Children in homeless families: risks to mental health and development. Journal of Consulting and Clinical Psychology, 61(2), 335-343.

Mensah, F. K., \& Kiernan, K. E. (2010). Parent's mental health and children's cognitive and social development. Social Psychiatry and Psychiatric Epidemiology, 45(11), 1023-1035. 
OECD. (2009). Doing better for children. Paris: OECD.

Oishi, S., \& Schimmack, U. (2010). Residential mobility, well-being, and mortality. Journal of Personality and Social Psychology, 98(6), 980-994.

Park, J. M., Fertig, A. R., \& Allison, P. D. (2011). Physical and mental health, cognitive development, and health care use by housing status of low-income young children in 20 American cities: a prospective cohort study. American Journal of Public Health, 101(S1), S255-S261.

Pearce, A., Elliman, D., Bedford, H., Law, C., \& Millennium Cohort Study Child Health Group. (2008). Residential mobility and uptake of childhood immunisations: findings from the UK Millennium Cohort Study'. Vaccine, 26(13), 1675-1680.

Pollack, C. E., Griffin, B. A., \& Lynch, J. (2010). Housing affordability and health among homeowners and renters. American Journal of Preventive Medicine, 39(6), 515-521.

Pribesh, S., \& Downey, D. B. (1999). Why are residential and school moves associated with poor school performance? Demography, 36(4), 521-534.

Rees, G., \& Bradshaw, J. (2017). Exploring low subjective well-being among children aged 11 in the UK: an analysis using data reported by parents and by children. Child Indicators Research, 11, 27-56. https://doi. org/10.1007/s12187-016-9421-z.

Reeves, A., Clair, A., McKee, M., \& Stuckler, D. (2016). Reductions in the United Kingdom's government housing benefit and symptoms of depression in low-income households. American Journal of Epidemiology, 184(6), 421-429.

Ridge, T. (2002). Childhood poverty and social exclusion: From a child's perspective. Bristol: Policy Press.

Rojas, Y., \& Stenberg, S. (2016). Evictions and suicide: a follow-up study of almost 22,000 Swedish households in the wake of the global financial crisis. Journal of Epidemiology and Community Health, 70(4), 409-413.

Ronald, R. (2008). The ideology of homeownership: homeowner societies and the role of housing. Basingstoke: Palgrave Macmillan.

Ryan, R. M., \& Deci, E. L. (2001). On happiness and human potentials: a review of research on hedonic and eudaimonic well-being. Annual Review of Psychology, 52, 141-166.

Sandel, M., \& Wright, R. J. (2006). When home is where the stress is: expanding the dimensions of housing that influence asthma morbidity. Archives of Disease in Childhood, 91, 942-948.

Scanlon, E., \& Devine, K. (2001). Residential mobility and youth well-being: research, policy, and practice issues. Journal of Sociology and Social Welfare, 28(1), 119-138.

Shaw, M. (2004). Housing and public health. Annual Review of Public Health, 25, 397-418.

Smith, S. J., Cigdem, M., Ong, R., \& Wood, G. (2017). Wellbeing at the edges of ownership. Environment \& Planning A, 49(5), 1080-1098.

Solantaus, T., Leinonen, J., \& Punamaki, R. L. (2004). Children's mental health in times of economic recession: replication and extension of the family economic stress model in Finland. Developmental Psychology, 40(3), 412-429.

Solari, C. D., \& Mare, R. D. (2012). Housing crowding effects on children's wellbeing. Social Science Research, 41, 464-476.

Swanson, C. B., \& Schneider, B. (1999). Students on the move: residential and educational mobility in America's schools. Sociology of Education, 72(1), 54-67.

Taylor, M. P., Pevalin, D. J., \& Todd, J. (2007). The psychological costs of unsustainable housing commitments. Psychological Medicine, 37, 1027-1036.

Unicef. (2007). Child poverty in perspective: an overview of child well-being in rich countries. Florence: Unicef.

Unicef. (2013). Child well-being in rich countries: A comparative overview. Florence: Unicef.

Unicef. (2016). Fairness for Children A league table of inequality in child well-being in rich countries. Florence: Unicef.

Warren, E. J., \& Font, S. A. (2015). Housing insecurity, maternal stress, and child maltreatment: an application of the family stress model. Social Service Review, 89(1), 9-39.

Wood, M., Turnham, J., \& Mills, G. (2008). Housing affordability and family well-being: results from the housing voucher evaluation. Housing Policy Debate, 19(2), 367-412.

Wood, G. A., Smith, S. J., Cigdem, M., \& Ong, R. (2015). Life on the edge: a perspective on precarious home ownership in Australia and the UK. International Journal of Housing Policy, 17(2), 201-226.

Ziol-Guest, K., \& McKenna, C. C. (2014). Early childhood housing instability and school readiness. Child Development, 85(1), 103-113. 